\title{
The Effectiveness of Cloud-Based E-Learning towards Quality of Academic Services: An Omanis' Expert View
}

\author{
Qasim A. Alajmi ${ }^{1}$ \\ Faculty of Computer Science \& MIS, \\ Oman College of Management \& Technology, \\ Sultanate of Oman
}

\author{
Adzhar Kamaludin², Ruzaini Abdullah Arshah³, \\ Mohammed A. Al-Sharafi ${ }^{4}$ \\ Faculty of Computer Systems \& Software Engineering, \\ University Malaysia Pahang, \\ LebuhrayaTunRazak, 26300, Kuantan, Pahang, Malaysia
}

\begin{abstract}
The purpose of this paper is to understand the importance, relevance and the need of implementing CloudBased E-Learning (CBEL) in Higher education institutions (HEIs) in Oman. The paper maintains its emphasis on addressing the effectiveness of the cloud based e-learning system and also takes into account the activities of comparing and contrasting the before and after effects of the implementation of the CBEL on higher educational sector in Oman. Method: The methodological approach of this paper follows qualitative approach of data collection and the data analysis techniques used in this paper are interpretivist approach and thematic analysis. Results and Findings: The data analysis techniques used in this research paper helped in understanding and gathering meaningful insights relating to the need and significance of implementing CBEL in educational sectors.
\end{abstract}

Keywords-Cloud computing; e-learning; cloud-based elearning; higher education institutions; quality of academic services

\section{INTRODUCTION}

A wide array of traditional educational platforms today is becoming obsolete and least suitable and worthy for fitting the requirements of consistent educational advancements [1], [2]. These conventional educational platforms are also becoming unable to go in-line with the variations of the learning demand in time and for this matter, the developments in the computer networking systems have brought revolutionary opportunities for it. E-learning in this case serves to be as a promising pattern for education [3], [4]. Cloud computing on the other hand, is associated with being as an enhanced base that enables the provision of and utilization of an adequate pool of computing resources [5]. Cloud computing promotes this practice with its effective scalability and its enhanced capability of utilizing resources that are virtualized, and these resources are used as a service through the Internet [6], [7]. The applications of cloud computing relate with the provision of flexibility to educational platforms as a whole. Cloud computing applications help in the prevention of challenges that are generally faced by conventional educational platforms [4]. For this matter, this research paper maintains its focus of attention on understanding the implementation of Cloud-Based E-Learning (CBEL) in HEIs in Oman and the relative effectiveness of the

This research has been supported by the Universiti Malaysia Pahang Research Grant RDU180310. work operations achieved with its implementation. The discussion carried out reflects on the information collected from authorities in the educational arena that provides insights on the combination of e-learning and cloud computing in an educational arena.

Following are the research questions that are proposed in the study: 1) How effective was the implementation of cloud computing based e learning? 2) What were the specific areas where cloud computing based e-learning enhanced work operations? The proposed study aims to understand the 'application and implementation of CBEL', specifically its adoption in the HEIs in Oman. Following are the objectives of this study: To understand the effectiveness of the CBEL that is implemented in educational sectors in Oman, to highlight specific key areas of improvement with HEIs in Oman and to compare and contrast the before and after effects of the implementation of CBEL in Oman.

\section{LITERATURE REVIEW}

\section{A. Cloud Computing and E-learning}

The cloud computing technology makes full potential use of technology and its relevant developments, which further makes use of existing remote servers that are centralized and internet in order to maintain the applications and information data. The cloud computing application enables and permits businesses and consumers to utilize applications, irrespective of the installation requirements. This practice also provides access to consumers and business so that they are enabled to access their personal informational data files on any computer, provided with an Internet connection. The cloud computing technology assures the efficiency of the computing processes by enabling the centralization of bandwidth, processing and data storage. Thus for this reason, cloud computing is associated with being as an element that makes use of hardware and software computing resources, that are transported through a network connection or Internet in the form of a service. Cloud computing derives its name from the shape of a cloud which serves to be as an image of the complex and compound infrastructure and framework. It contains in its system diagrams Cloud computing with user's informational data, computation and software applications, highly relies on the remote services. 
E-learning on the other hand makes use of technologies that assists and helps in online assessment, education, learning and knowledge extraction. In this way, e-learning makes potential use of the existing innovative educational technology and enormous amount of resources; this in turn enables newer and better ways for teaching [8]. E-learning thus can be associated with the form of education and learning that is network based, assuring the use of technological advancements. In addition to this, the cloud computing system in educational institutions and campuses is delighted with the provision of an effective infrastructure and framework, moreover it also relates with the provision of a delivery model that reflects on their dynamic demands. There exist wide arrays of benefits and advantages that are associated with the application of cloud computing. As far as the use of cloud computing in educational and learning arena is concerned, it provides increased level of support for educational platforms, so as to help them in devising certain prevention strategies against some of the commonly held challenges. Furthermore, the challenges faced by educational institutions range from rapid and effective communication, reduction in cost incurring, provision of flexibility, provision of accessibility, privacy and security concerns.

\section{B. Higher Education in Oman}

The expansion associated with the (HEI's) is regarded with being as rapid and swift in the Arab economies. The underlying reason behind this rapid expansion is the increased education's social demand and the emerging governmental preferences in order to support and develop the effectiveness and efficiency of the human resources as per the requirements of their relative economies. It is the administrative and financial capacity and capability of these economies to successfully respond to this emerging need and this has been well discussed and has been a part of literature. A wide variety of approaches are adopted and used in order to upgrade the quality of higher education. Majority of the Arab countries make use of wide arrays of approaches in order to improve the quality of higher education. One of the approaches reflects on the shift and transmission of education that has been made to private sector, this helps in preventing the issue arising due to emerging demand. In addition to this, there still exists a universal disapproval associated with the quality of higher education in Gulf countries and in Oman in particular, despite of the consistent efforts and attempts made for upgrading the quality of higher education [9].

All of the member states of the Gulf Cooperation Council (GCC) are experiencing an increased and swift transformations and expansions in their higher educational sectors. Moreover, there lies multiple questions that are related with what factors to focus on when teaching and how to carry out the activities associated with teaching process. With the development and formation of the educational institutions, including setting up their infrastructure, there also exist certain emerging concerns that arise due to maintenance and sustainability of the quality control and its accountability. A wide number of Higher Education Sectors now seek to assure the containment of wide range, diverse and varying levels of Higher Education Institutions with varying curricula [10]. The central questions that emerge could relate to explaining the enforcement of the teaching standards and the measurement of the research output.
The concept and idea of forming international partnerships are of high significance to the Gulf Cooperation countries' universities and colleges. Some of the Gulf member countries have resulted in successfully attracting the western/foreign universities, on the other hand, other member states are still stuck with unaccredited educational platforms from around the world [11]. In Oman there are 29 private universities/colleges affiliated with western universities.

It is because of the apparent failure of the public educational institutions in meeting the requirements for highly qualified graduates of universities that are required for the development in social and economic terms. On the other hand, a majority of the international and private educational institutions including colleges and universities have efficiently succeeded in attracting a wide range of students and have also increased in number, because of their ability to naturally respond to the escalating ideas and concepts of globalization, privatization, agreeableness of adoption towards the foreign culture. As far as the higher education system is Oman is concerned, it is undergoing significant refinement phase. Oman is making relevant efforts to accommodate and catering the increasing young national population by enlarging the base for primary and secondary schools. As per the data census of the past three decades, Oman is seen as flourishing and observed to be followed by swift developments in its higher education system [11]. The country has formed an overall independent system which includes more than 60 Higher Educational Institutes (Public and Private) they successfully provide varying degree programs. For a majority number of authorities belonging from different parts of the world, the improvements and enhancement of quality of the overall education system has served to be as a prior concern. In order to fortify the national and social identity among a wide range of individual learners, a wide majority of countries are taking necessary steps in order to strengthen and refine the education systems and quality. As a matter of fact, this practice further leads to enabling individual learners to efficiently respond to consistently changing political, economic and technological environments and overall swiftly changing demands of the future [4].

\section{Analysis of Higher Education in Oman}

As per the analysis of the above mentioned Higher Education system in Oman, a complete SWOT analysis can be drawn out to understand the overall environment of higher education in Oman and also identify the need and growth level of implemented CBEL in Oman. As discussed in the section above, the growing population of the young nationals in Oman serves to be as a dynamic opportunity for the country. This opportunity can thus be used as a strengthening element to cash on making further developments in the higher education system and make use of the implementation and application of the CBEL. In addition to this another strengthening element for Oman is its ability and efforts in developing independent educational system that comprises of wide variety of (HEI). The increased range of developed higher educational institutes in Oman can catch the benefits of implementing and successfully utilizing the CBEL.

In addition to this, one of the weaknesses of the higher education system in Oman is the widely accepted level of criticism on the quality of education among majority of the 
Gulf countries. This element also serves to be as an emerging threat for Oman, because of the perceived quality of education system and the resulting impact of it. Furthermore, another emerging potential threat can be the possible inability of Oman's education system to understand, identify and develop relevant prevention strategies for problems and risks that are associated with the implementation of CBEL. As a matter of fact, Oman's overall educational system is flourishing and is under development, thus there lie higher chances of less familiarity with the issues and risks that are related with the CBEL.

\section{Current E-Learning Environment}

As briefly discussed in the sections above, e-learning is associated with being as a learning system that is electronically supported-learning undertakes the necessary intersections with varying elements of practice, such as, learning, teaching, assessment, technology and knowledge [12]. The transmission of relevant network based skills, knowledge base, learning abilities is enabled by the computer based e-learning processes. These network based processes reflect the containment of applications which include computer based learning, web and network based learning, virtually enabled education opportunities and thus promoting digital based collaboration. Synchronous and asynchronous are the two broad categories that are used to understand the concepts and usage of elearning. Furthermore, synchronous e-learning related with the learning process that enables and individual learner to indulge in a course available online and with the help of streaming video and audio online and communicating with the faculty member online at a specific period of time. The synchronous elearning appears to be as a learning process that provides numerous advantages for the learner, but on the other hand it does have a major disadvantage associated with it too. The most crucial disadvantage associated with synchronous elearning is the inability of this e-learning category to provide time flexibility [13], as the entire learning process activities are carried out at a specific time period. On the other hand, asynchronous e-learning process provides a student with the advantage of time flexibility, thus an individual learner is enabled to participate in the online learning process by assuring the learning processes are carried out at an appropriate and suitable time for a learner. Moreover, asynchronous e-learning is also exposed to a major disadvantage, which relates with the lack of immediacy and timely respond rate of a faculty member.

\section{E. Cloud Computing Educational Environment}

Cloud computing has served to be as a dynamically developing subject that has successfully attracted a wide range of individuals from different parts of the world and belonging from different disciplines. The provision, transmission and management of varying computer resources such as, processing, servers, storage, applications and networking, are all transformed with the cloud computing applications. Moreover, educational cloud is associated with being as one of the most attractive and prominent applications of cloud computing [14]. The underlying reason of educational cloud being as the most interesting application of cloud computing is its power of undertaking and possessing the emphasis of thousands of computers on one problem. Thus, this practice followed by educational cloud, enables it to permit the searches of different researchers, seeking relevant models, discovering at a rapid rate and hence helping in the development of a smarter planet. A wide variety of educational platforms can now unlock doors for their technological infrastructures for public and private sectors in order to undertake the research developments.

The consistently changing, increasing and demanding resources requirements and ever growing energy costs can now efficiently be met by universities with the efficiencies of cloud computing application. It is because of this matter that now students and individual learners are now enabled to make use of their mobile devices and stay connected with the campus's educational services [15]. Furthermore, the faculty members are now consistently demanding and requiring to be provided with efficient level of flexibility and access while undertaking technology integration into the classes. The services of the educational cloud computing reflect upon the increasing variety of services that exist on the Internet, along with the most swiftly growing innovative part of education and technology. Moreover, educational cloud also assures the provision of varying levels of services, which are associated with being as advantageous and beneficial for individual learners, staff and faculty members. The overall benefits and the role that cloud computing plays should be prominently highlighted because; it enables the provision of direct accessibility to wide arrays of multiple academic resources, educational tools and research applications.

The educational and learning arena is undertaken by the educational cloud computing on a next level, because of the advancements and developments in the applications, platforms, services and overall academic based cloud computing services. Today, a wide variety of individual learners/students, faculty members and researchers are making complete potential use of cloud computing based services and applications. In addition to this, a heavy investment in cloud computing is followed by these applications because of the increased dependability of the future of academic learning research on cloud computing [16]. On the other hand, the application of cloud computing is regarded with being as a new model that is threatening the role performance of educational institutions and faculty members to be very specific. This practice of cloud computing poses varying levels of challenges to the computing service personnel who in one way might fear the outcomes of their job roles being outsourced. Furthermore, some of the developers might also feel increased discomfort level the transference of operationally critical informational data and services beyond the institution's boundaries. Hence, there exist certain challenges that are associated more with the perceptions that are developed rather than the reality.

\section{METHODOLOGY}

\section{A. Research Design}

The research design of this study is designed on the basis of qualitative data gathering through Semi-structured interviews and qualitative analysis of the collected data. The data collection instrument used is the interview questions. In order to contribute to the meaningfulness of the subject study and motive of the study, the use of qualitative research was 
followed. The use of qualitative research data collection also contributes to the significance of this study, because it enables to cater and include the fresh information and the new findings that will emerge with time, thus the study overall will assure rapid revision. The semi-structured interview questions designed to take into consideration the change and development in the effectiveness of higher education system in Oman and on what specific areas the refinement of the education system is highlighted. In addition to this, the interview questions also developed in a way that they will gather information on the areas for further improvements that are needed to be taken into account in order to assure efficient implementation of the CBEL.

\section{B. Sample}

As a matter of fact, the sampling process in carrying out a research study on data collection is regarded with being as both, crucial, complex and of high relevance. Thus in order to meet the data collection requirements of the subject study, the process of sampling needs to be adequate, it needs to highly reflect and generate relevant and meaningful information. For this reason, to maintain quality of the respondent's views and to get a deeper and meaningful insight into each interview question, a sample of 10 experts, which serve as regulatory authority in the higher education system in Oman. The study conducted maintained its focus on primary data collection and dependent on making use of qualitative data collection techniques and qualitative analysis, so as in order to generate meaningful qualitative views and responses from respondents. Table I contains further details on the kinds of participants in this study. The identity information of the experts was detached and a distinctive ID for differentiating the quotes of each participant was included for the purpose of confidentiality.

TABLE I. INTERVIEWEES’ PROFILE

\begin{tabular}{|c|c|c|c|}
\hline $\begin{array}{l}\# \\
\text { ID }\end{array}$ & Description & Experience & Reason for Inclusion \\
\hline 1 & $\begin{array}{l}\text { Director General for Public } \\
\text { and Private universities and } \\
\text { colleges in MoHE in Oman. }\end{array}$ & $22 \mathrm{yrs}$ & $\begin{array}{l}\text { Due to her direct involvement } \\
\text { in HEIs issues. }\end{array}$ \\
\hline 2 & $\begin{array}{l}\text { Director General for Applied } \\
\text { colleges in MoHE in Oman. }\end{array}$ & $30 \mathrm{yrs}$ & $\begin{array}{l}\text { Due to his various } \\
\text { designations had in IT } \\
\text { developments for higher } \\
\text { education in Oman. }\end{array}$ \\
\hline 3 & $\begin{array}{l}\text { Director General for } \\
\text { strategic planning in MoHE } \\
\text { in Oman. }\end{array}$ & $28 \mathrm{yrs}$ & $\begin{array}{l}\text { Due to his membership in lots } \\
\text { of committees of education } \\
\text { nature. }\end{array}$ \\
\hline 4 & $\begin{array}{l}\text { Director for IT directorate in } \\
\text { MoHE in Oman. }\end{array}$ & $26 \mathrm{yrs}$ & $\begin{array}{l}\text { Due to his achievement in } \\
\text { ELearning in some of the } \\
\text { Public colleges. }\end{array}$ \\
\hline 5 & $\begin{array}{l}\text { Ex-Under secretary in } \\
\text { MoHE in Oman. }\end{array}$ & 35 yrs & $\begin{array}{l}\text { Due to his actively involved in } \\
\text { Educational council. }\end{array}$ \\
\hline 6 & $\begin{array}{l}\text { Ex- Director for IT } \\
\text { directorate in MoHE in } \\
\text { Oman. }\end{array}$ & $35 \mathrm{yrs}$ & $\begin{array}{l}\text { He is one of the figures in } \\
\text { Oman IT programs initiatives. }\end{array}$ \\
\hline 7 & $\begin{array}{l}\text { Consultant in MoHE in } \\
\text { Oman. }\end{array}$ & $30 \mathrm{yrs}$ & $\begin{array}{l}\text { Full experienced in Cloud } \\
\text { services. }\end{array}$ \\
\hline 8 & Expert in MoHE in Oman. & 32 yrs & $\begin{array}{l}\text { Dues to his involvement with } \\
\text { top decision makers in the } \\
\text { ministry. }\end{array}$ \\
\hline 9 & Expert in MoHE in Oman & 38 yrs & $\begin{array}{l}\text { Chair of design curriculum } \\
\text { committee. }\end{array}$ \\
\hline 10 & $\begin{array}{l}\text { Academic advisor in MoHE } \\
\text { in Oman. }\end{array}$ & $40 \mathrm{yrs}$ & $\begin{array}{l}\text { Supervisor of Academic issues } \\
\text { for HEIs in Oman. }\end{array}$ \\
\hline
\end{tabular}

\section{Reliability and Validity}

Content validity established by seeking help from experts to review the research instruments so that any obscure and unclear questions are revised. Internal validity established through triangulation as different sources are used to collect data that are interviews and survey in case of proposed study. Also, researcher's biasness controlled by practicing impartiality when collecting, analyzing and interpreting data. External validity ensured by applying the findings in other settings and assessing the similarities between current research context and another context; besides validity, proposed study also ensured reliability; external reliability established by describing the participants fully about the study and by explicitly explaining the methods of data collection. Internal reliability established though recording of data mechanically so that it is possible to re-analyze it if required. Also, peer examination followed by applying and utilizing findings from other researchers.

\section{Data Analysis}

The discussion carried out in the sections above suggest that the data collection was qualitative in nature and for this matter the data collected from a sample of 10 expert's members with regulatory authority belonging from the higher education system in Oman in the form of interview questions. The analysis of a qualitative data is crucial to researchers but on the other is equally of high value and significance too. To ensure the qualitative collection of information and extraction of meaningful data, the data analysis done based on interpretivist research methodology and thematic analysis. Thus in order to make the data analysis of the qualitative information/data extracted, a theme based structure will be designed for the 8 [see Appendix A] interview questions and based on the theme of those questions the answers generated is analyzed and evaluated. Thematic analysis maintains focus of attention on highlighting, identifying, scrutinizing and in recording themes or patterns within the data [17]. Themes are developed for each interview question and they are of significance because they help in explaining a specific phenomenon that is related with the research question. And thus in this way the themes turn into separate broad segments for analysis.

Whereas on the other hand, interpretivist approach is also used in this research paper to qualitatively analyze the data. As a matter of fact, interviews among other primary data collection methods are used in the interpretivist approach. The interpretivist approach to data analysis of the research study is subjective based study that relates with deriving meaning and understanding from the research study data. With this approach that is being used as a qualitative data analysis technique, the primary goal of the analysis is to develop and understanding instead of making predictions. Using an interpretivist approach, the information generated from the sample data is not considered to be permanent but $\mathrm{s}$ rather taken as an information piece that is relative to time, context, culture and the overall situation in which the research study was carried out.

\section{RESULTS AND DISCUSSION}

This section deals with highlighting the key results generated from the interview questions and analyzing the 
answers of respondents, keeping in view the research study's subject. As mentioned in the discussion earlier that the respondent's answers and views analyzed by using interpretivist approach and the overall analysis based on a thematic analysis. For a number of obvious reasons, the subject of the research is associated with the implementation of the CBEL systems in higher educational system in Oman specifically, thus the interview questions are also designed on the similar pattern. Multiple themes are developed and used to extract meaningful answers and insights from the responses of respondents. These themes roughly revolve around the importance of CBEL for educational sector as a whole, how effective the system is in promoting flexibility and innovation in operations and how efficient the CBEL is promoting cost reduction. Table II summarizes the respondent's responses to the interview questions:

TABLE II. RESPONDENTS' RESPONSES

\begin{tabular}{|c|c|}
\hline Qs & Respondents' responses \\
\hline $\begin{array}{l}\text { How effective is the } \\
\text { implementation of (CBEL) in } \\
\text { (HEIs) in Oman? }\end{array}$ & $\begin{array}{l}70 \text { Present, Highly supported views on the fact } \\
\text { that implementation of CBEL system has } \\
\text { increased the effectiveness and efficiency. }\end{array}$ \\
\hline $\begin{array}{l}\text { What is the level of significance of } \\
\text { ELBCC for successful } \\
\text { undertaking of operations in } \\
\text { HEIs? }\end{array}$ & $\begin{array}{l}50 \text { Present, Shows high level of agreeableness in } \\
\text { supporting the significance of ELBCC for } \\
\text { successful implementation of in educational } \\
\text { sectors in Oman. }\end{array}$ \\
\hline $\begin{array}{l}\text { What are the future expectations } \\
\text { for upgrading the implementation } \\
\text { process and operations of CBEL? }\end{array}$ & $\begin{array}{l}50 \text { Present, expressed that no need to worry al all } \\
\text { about upgrading and implementation, as this } \\
\text { became part of SLA. }\end{array}$ \\
\hline $\begin{array}{l}\text { What is the significance of heavy } \\
\text { investments made by educational } \\
\text { sector to implement e-learning } \\
\text { system? }\end{array}$ & $\begin{array}{l}50 \text { Present, Agreeableness and supporting } \\
\text { statements to making increased investments in } \\
\text { promoting the implementation of CBEL } \\
\text { application in educational platforms. }\end{array}$ \\
\hline $\begin{array}{l}\text { How significant is CBEL in } \\
\text { promoting flexibility and } \\
\text { innovation in routine operations? }\end{array}$ & $\begin{array}{l}50 \text { Present, Agreeableness and supporting } \\
\text { statements to making increased in promoting the } \\
\text { flexibility and innovation of CBEL application in } \\
\text { educational platforms in routine operations }\end{array}$ \\
\hline $\begin{array}{l}\text { How efficient is the adoption of e- } \\
\text { learning over cloud in providing } \\
\text { increased and convenient access to } \\
\text { resources for students and faculty } \\
\text { members? }\end{array}$ & $\begin{array}{l}50 \text { Present, Supported on the fact that the } \\
\text { implementation and operations of CBEL provide } \\
\text { convenience and increased access to relevant } \\
\text { informational data to individual learners and } \\
\text { faculty members altogether. }\end{array}$ \\
\hline $\begin{array}{l}\text { How efficient is CBEL in cost } \\
\text { reduction for educational } \\
\text { institutions? }\end{array}$ & $\begin{array}{l}70 \text { Present, Highly supported views on the cost } \\
\text { reduction due to adopt ELBCC in HEIs in Oman. }\end{array}$ \\
\hline $\begin{array}{l}\text { What is the level of impact of the } \\
\text { risks and threats associated with } \\
\text { CBEL in Oman? }\end{array}$ & $\begin{array}{l}50 \text { Present, Emphasized on the impact and } \\
\text { significance of understanding the risks and threats } \\
\text { that are associated with the implementation and } \\
\text { functioning of the CBEL systems. }\end{array}$ \\
\hline
\end{tabular}

The first question emphasizes upon generating deeper insights from the respondents on their opinion about the effectiveness of implementation of CBEL. The responses generated from the respondents showed highly supporting views on the fact that implementation of cloud based e-learning system has increased the effectiveness and efficiency of the operations that are undertaken by the educational sectors. This directs the attention on the past researchers that have been carried out. As discussed in the earlier sections, an CBEL proves to be effective in carrying out the processes in the educational institutions [18]. The implementation of e-learning highly supports and increased the effectiveness of the operations of assessment, learning and educating the individual learners. The responses of individuals on this question also support the past researches by proving the increased effectiveness of learning and educating processes to the individual learners that are geographically dispersed.

Another key interview question is themed on understanding the rate of effectiveness of CBEL in promoting the elements of flexibility and innovation in operations that are undertaken in overall higher educational system. The respondents showed high level of agreeableness and expressed positive responses on the ability of e-learning and its implementation effects in higher education system of Oman. The positive responses from respondents direct the focus of attention on the past researches and prove that the implementation of the cloud based elearning system in educational platforms assures the use of technological advancements and innovative measures to carry out the routine operations [19]. As mentioned in the earlier section, the use CBEL because of its increased dependency and reliance on utilization of technology has resulted in successfully attracting significant momentum. The CBEL has also proved to provide time flexibility to individual learners. The responses of respondents on this questions supports the previous researches which claims that e-learning provides the advantage of time flexibility to students that are geographically dispersed. As per the discussion carried out in the paper earlier, an asynchronous e-learning process enables a student to get involved in a learning practice as per time that suite the student. Thus e-learning implementation in educational arena helps in promoting the elements of innovation and providing flexibility of operations, especially in terms of time.

In addition to the above, the respondents also showed high level of agreeableness and gave positive answers in supporting the significance of making increased investments in implementation of CBEL systems in educational sectors in Oman [20]. As a matter of fact, the market today is focused on directing its efforts on understanding the technological changes that are taking place and also on how to make full potential use of these technological advances in order to reap the benefits of technological developments. The educational sector in Oman is flourishing and so is the population growth rate of young nationals, thus it is of high significance for the regulatory bodies (respondents) to identify and understand the rapid developments and changes in the technological demands of the educational sector and also assure the timely implementation of the technological systems. The respondents supported the fact that it is of high importance for governing bodies and regulatory authorities in the educational sector to make necessary input and promote increased investments in order to support the implementation plan related with the CBEL.

Besides this, the respondents' agreeableness and supporting statements to making increased investments in promoting the implementation of CBEL application in educational platforms also reflected on highlighting the further importance of the elearning system in relation to distance learning. With the emerging need of distance education, there arises a need of assessment and learning too. It suggests that the concept and applications of learning and educating with the help of technological advances can now be applied to varying levels of instructional settings, without the geographical constraints [21]. In addition to this, there exist certain key elements of elearning that are of utmost relevance and significance in distance education. The e-learning strategy to be followed is 
intent on by the media sources used for its delivery, available resources and the availability of time and its adequate management.

Furthermore, the respondents also emphasized on the impact and significance of understanding the risks and threats that are associated with the implementation and functioning of the CBEL systems. The responses generated from the interview questions, reflected on the fact that is highly important to not only identify the risks and threats associated with the elearning system but on also devising prevention strategies to cater them and minimize their adverse impact [22]. The responses generated under this question direct the focus of attention on varying levels of security threats and risks that adversely affect the functionality of CBEL system in educational institutions. There exist wide arrays of security risks, such as user authentication or authorization, manipulation on part of students, confidentiality of the information data that is kept private and the threat of integrity in terms of editing or making alterations in the informational data that is kept private.

These are some of the most commonly held prominent risks and threats associated with the implementation of e-learning system. In addition to this, the previous researches also suggest the need for the adoption of certain prevention strategies to overcome or minimize the effect of these security and authenticity threats [22]. The prevention strategies include the information security mechanism using SMS, this helps in the provision of generating special passkeys to registered cellular phone numbers and helps in providing authorized access to informational data. Another prevention strategy relates with undertaking information security mechanism using biometrics, which helps in providing authorized access to informational data depending on its ability to recognize an individual based on physical and behavioral features. And lastly, the use of mechanism that is related with access control list also provides prevention measures for avoiding the issues arising due to security threats of the CBEL system.

Moreover, the respondents also supported on the fact that the implementation and operations of CBEL provide convenience and increased access to relevant informational data to individual learners and faculty members altogether. This directs the attention on the overall benefits that cloud based e-learning brings for students and faculty members despite of the geographical boundaries that exist. The CBEL application helps support students in providing them with resources that include the online access to video and audio lectures and services of an online assessing examinee to assess and mark the performance of an individual learner [23]. The access of resources for students and faculty members relates with the idea of promoting the benefits that are associated solely with the use of e-assessment, e-marking and esubmission through the implementation of CBEL systems in educational institutions.

The respondents also generated positive responses that were in support of the question related to the significance, importance and need for implementing the CBEL system. The responses reflect upon the wide range of benefits are associated with the usage of electronic marking and electronic submission. First relates with the provision of convenience, cost management and flexibility for students, thus they do not need to carry out the printing processes of their work or submitting assignments and seeking access to feedback. In addition to this, [24] states that the processes of e-submission and e-marking provides benefits to both, instructors and individual learners in keeping adequate track record of the relevant submissions and progress made. Also, authenticity of the content can also be assessed by using plagiarism software to identify any text matches. This practice helps in maintaining the academic integrity levels. Another advantage of using esubmission and e-marking is the retained access that is provided to staff specifically in order to provide further feedback, marking and accessing the files for future references. Another benefit relates with the portability element for instructors and examiners. Online submission and marking of the papers provides examiners with ease of carrying out the assessment processes with convenience. Thus, as per the data collection and gathering relevant opinions and responses from the respondents, the entire research study and the data collection process reflects on showing increased support for the need and importance for educational sectors to undertake the implementation and implication of the CBEL system.

\section{RECOMMENDATIONS}

In addition to extracting the meaningful and deeper insights of the opinions of the regulatory authorities in the higher education system of Oman and also making additional arguments in support of the literature data that is of relevance to the research study's subject, the paper also highlighted on making necessary recommendations that could positively contribute to the study subject. The recommendations revolve around maintaining focus on identifying and understanding the threats that are associated with the implementation process, functionality and overall operations of the CBEL system. The educational platforms need to follow and support the application of e-learning in educational sectors but there also lies an immense need to keep into consideration the threats and risks of security that come along with e-learning implementation and operations. Thus, it is highly recommended to educational platforms to devise necessary steps and prevention strategies in order to eliminate or minimize the impact of risk and threats.

\section{CONCLUSION}

This study maintained its focus on understanding the implementation of the CBEL system, with an emphasis on its adoption in HEIs in Oman. As mentioned in the sections above that the data on the research study's subject was collection through carrying out qualitative interviews from the regulatory authorities in the HEIs in Oman. For this matter, the results generated from the respondents showed high level of agreeableness with the level of significance and importance that is associated with CBEL implementation in educational arena. The responses of the respondents reflected on positivity of the importance of making use e-learning systems in the educational institutions and the benefits that are generated with its application. In addition to this the data collection on the research paper also highlights the benefits that the implementation of cloud based CBEL brings for educational 
sector as a whole. The understanding and efficient utilization of the e-learning system has helped Oman's educational arena to go parallel with the consistent changes that have been taking place in technological, social, political and economic environments. Also, the implications of the CBEL also reflect on promoting and contributing towards the development and growth of Oman's education system and have also contributed in promoting the Oman's overall educational sector refinement. Moreover, the research paper not only contributes in the extraction of the respondent's views and limits the responses on the interview questions, but the paper it helps in generating deeper meaningful insights from the open ended interview questions and helps provide supporting arguments in support of the past relevant researches that have been carried out previously. Hence, the research paper helps in proving the importance, significance and need for educational sectors (specifically for the higher education system in Oman); to encourage decision makers for adoption of CBEL.

\section{ACKNOWLEDGMENT}

The authors would like to express their cordial thanks to Oman College of Management \& Technology, Sultanate of Oman. We also would like to thank Universiti Malaysia Pahang (UMP) for supporting this work through Research Grant Scheme RDU180310.

\section{REFERENCES}

[1] Q. Alajmi, Sadiq, S., \& Alsharafi, M., "Cloud Computing delivery and Delivery Models: Opportunity and Challenges," in International Conference on Science, Engineering, Management and Social Sciences, Malaysia: university Teknologi Malaysia., 2016, pp. 15-16.

[2] Q. Alajmi and A. Sadiq, "What should be done to achieve greater use of cloud computing by higher education institutions," in Information Technology, Electronics and Mobile Communication Conference (IEMCON), 2016 IEEE 7th Annual, 2016, pp. 1-5: IEEE.

[3] A. P. Rovai, M. K. Ponton, M. J. Wighting, and J. D. Baker, "A comparative analysis of student motivation in traditional classroom and elearning courses," International Journal on ELearning, vol. 6, no. 3, p. 413, 2007.

[4] Q. AlAjmi, R. A. Arshah, A. Kamaludin, A. S. Sadiq, and M. A. AlSharafi, "A Conceptual Model of E-Learning based on Cloud Computing Adoption in Higher Education Institutions."

[5] M. A. Al-Sharafi, R. A. Arshah, and E. A. Abu-Shanab, "Factors Influencing the Continuous Use of Cloud Computing Services in Organization Level," presented at the Proceedings of the International Conference on Advances in Image Processing - ICAIP 2017, Bangkok, Thailand, 25 - 27 Augst, 2017.

[6] Q. Zhang, L. Cheng, and R. Boutaba, "Cloud computing: state-of-the-art and research challenges," Journal of internet services and applications, vol. 1, no. 1, pp. 7-18, 2010.

[7] M. A. Al-Sharafi, R. A. Arshah, and E. A. Abu-Shanab, "Factors affecting the continuous use of cloud computing services from expert's perspective," in TENCON 2017 - 2017 IEEE Region 10 Conference, 2017, pp. 986-991.

[8] V. Arkorful and N. Abaidoo, "The role of e-learning, advantages and disadvantages of its adoption in higher education," International Journal of Instructional Technology and Distance Learning, vol. 12, no. 1, pp. 2942, 2015.

[9] T. Sivakumaran, G. Holland, W. Wishart, K. Heyning, and B. FlowersGibson, "Electronic Assessment Systems: Implementation, Maintenance and Support," FOCUS on Colleges, Universities \& Schools, vol. 6, no. 1, 2011.
[10] I. Shah and N. Baporikar, "The suitability of imported curricula for learning in the Gulf states: An Oman perspective," Teaching and learning in the Arab world, pp. 275-292, 2011.

[11] H. PATEL, A. PATEL, and P. SHAH, "IMPACT OF E-LEARNING IN THE DEVELOPMENT OF STUDENT LIFE," International Journal of Research in Engineering \& Technology, vol. 2, no. 4, pp. 233-238, 2014.

[12] A. Fernández, D. Peralta, J. M. Benítez, and F. Herrera, "E-learning and educational data mining in cloud computing: an overview," International Journal of Learning Technology, vol. 9, no. 1, pp. 25-52, 2014.

[13] S. Hrastinski, C. Keller, and S. A. Carlsson, "Design exemplars for synchronous e-learning: A design theory approach," Computers \& Education, vol. 55, no. 2, pp. 652-662, 2010.

[14] T. Ercan, "Effective use of cloud computing in educational institutions," Procedia-Social and Behavioral Sciences, vol. 2, no. 2, pp. 938-942, 2010.

[15] U. J. Bora and M. Ahmed, "E-learning using cloud computing," International Journal of Science and Modern Engineering, vol. 1, no. 2, pp. 9-12, 2013.

[16] A. Abbas, K. Bilal, L. M. Zhang, and S. U. Khan, "A cloud based health insurance plan recommendation system: A user centered approach," (in English), Future Generation Computer Systems-the International Journal of Escience, vol. 43-44, pp. 99-109, Feb 2015.

[17] G. Guest, K. M. MacQueen, and E. E. Namey, Applied thematic analysis. sage, 2011.

[18] M. A. H. Masud, M. R. Islam, and J. Abawajy, "Security Concerns and Remedy in a Cloud Based E-learning System," in International Conference on Security and Privacy in Communication Systems, 2013, pp. 356-366: Springer.

[19] M. Al-Zoube, S. A. El-Seoud, and M. F. Wyne, "Cloud computing based e-learning system," International Journal of Distance Education Technologies (IJDET), vol. 8, no. 2, pp. 58-71, 2010.

[20] W. Horton, E-learning by design. John Wiley \& Sons, 2011.

[21] G. C. Moore and I. Benbasat, "Development of an instrument to measure the perceptions of adopting an information technology innovation," Information systems research, vol. 2, no. 3, pp. 192-222, 1991.

[22] N. Barik and S. Karforma, "Risks and remedies in e-learning system," arXiv preprint arXiv:1205.2711, 2012.

[23] D. R. Garrison, E-learning in the 21st century: A framework for research and practice. Taylor \& Francis, 2011.

[24] N. Sultan, "Cloud computing for education: A new dawn?," International Journal of Information Management, vol. 30, no. 2, pp. 109-116, 4// 2010.

\section{APPENDIX A}

Interview Questions

- How effective is the implementation of Cloud-Based E-Learning (CBEL) in Higher Education Institutions (HEIs) in Oman?

- What is the level of significance and importance of e-learning for successful undertaking of operations in an educational arena?

- What are the future expectations for upgrading the implementation process and operations of CBEL?

- What is the significance of heavy investments made by educational sector to implement e-learning system?

- How significant is CBEL in promoting flexibility and innovation in routine operations?

- How efficient is the adoption of e-learning over cloud in providing increased and convenient access to resources for students and faculty members?

- How efficient is CBEL in cost reduction for educational institutions?

- What is the level of impact of the risks and threats associated with CBEL in Oman? 